\title{
EDITORIAL
}

\section{Chronic effects of ozone in children}

\author{
J. Sunyer
}

Children are not little adults in terms of environmental exposure. They have a unique vulnerability, given their developmental stage and their higher exposure. Lung function in childhood increases linearly with age and height until the adolescent growth spurt [1]. Studies on failure to maintain the predicted lung-function growth-curve during pre-adolescence are pertinent, both from a research and a public health perspective and are easier to conduct than studies in adulthood, given the absence of smoking. Ozone is the most important photochemical oxidant in the troposphere. It is formed by photochemical reactions in the presence of precursor pollutants released by motor vehicles. As a result of its photochemical origin, $\mathrm{O}_{3}$ concentrations are much higher in summer.

Change in lung function (forced vital capacity, FVC; forced expiratory volume in one second, FEV1, mean maximal expiratory flow) between a pre- and a post-summer test was negatively associated with the cumulative $\mathrm{O}_{3}$ mean in a study conducted in Austria [2]. In nine areas without major industrial sites, 1,150 children aged between 8-11 yrs were followed during a $3-y r$ period, performing 6 lung function tests. A further analysis showed the effect of $\mathrm{O}_{3}$ to be independent of particles and nitrogen dioxide [3]. These results were not replicated by the first of the South California cohort studies [4] where more than 3,000 children from 12 communities were followed during 4 yrs and lung-function tests were performed annually. However, in the same study in South California, lung function level was lower in communities with higher ozone in comparison to communities with lower $\mathrm{O}_{3}$ average levels; particularly among young females with asthma and spending more time outdoors [5].

A major difficulty in studies on the chronic effects of air pollutants, is how to measure the cumulative exposure of each child. The spatial variability of ozone levels may be high within large areas, since there are gradients within cities, due to the reaction of ozone with nitrogen oxides, particularly in town centres with dense traffic [6]. This is obviously an obstacle in designing epidemiological studies based on differences in exposure for different communities. It has been suggested that a valid measure could be obtained by weighting ozone monitor levels by the time spent by subjects in the different areas [7]. The misclassification error of exposure could lead to a positive or negative bias, though the few epidemiological studies that have explicitly assessed the misclassification error found a bias towards the null hypothesis $[8,9]$ and therefore penalising an actual association.

Standardisation of lung-function tests when doing withinindividual comparisons is a complicated endeavor in these studies. Not only do spirometers and technicians have to be the same, strict quality control must also ensure avoidance of

Institut Municipal d'Investigatio Medica, Universitat Pompeu Fabra, Barcelona, Spain.

Correspondence: J. Sunyer, Inst. Municipal D'Investigacio Medica, c/ Doctor Aiguader 80, E-08003, Barcelona, Spain. Tel: +34 932211009. Fax: +34 932216444 . the common fatigue effect occurring in long, cohort studies. Poor reliability, of particular concern in comparisons of only two lung-function tests, can really only be avoided through perfect field work. In addition, the growth spurt in adolescence, which generally occurs at the age of 10 yrs in young females and 12 yrs in young males, has enormous individual variability which creates problems in interpreting the results [1].

In this issue, IHORST et al. [10] from the same team that carried out the pioneer Austrian study, publishes results from a larger population (2,251 children from 14 rural and mediumsize areas, 5 German and 9 Austrian), followed during a longer period (including four summers) and performing more refined statistical analysis (including regression methods for repeated measurements and models to estimate lung growth over the total study period). An effect of $\mathrm{O}_{3}$ in reducing the pre-summer lung function (FVC and FEV1) in comparison with the post-summer test was only found in the first two of the four summers, namely those with higher ozone levels. In addition, a catch-up effect of lung function during winter among those with a slower growth during summer and the absence of any cumulative effect for the whole period is reported. The authors conclude that the medium-term effect found at the end of summer is reversible and has no chronic impact. Potential mechanisms of how repeated acute insults of ozone to the respiratory system results in chronic damage and persistent impairment of lung function are unknown.

IHORST et al. [10] measured exposure using the central monitoring stations both as mean-semiannual $\mathrm{O}_{3}$ concentrations for the inhabitants of a given area and by classifying the communities in three exposure groups. Results were consistent using both methods. However, the authors were unable to estimate individual exposures by weighting per time spent outdoors in each community per each individual.

Subgroup analysis might provide a different appraisal of $\mathrm{O}_{3}$ effects. The second cohort study in South California following 9-10 yr old children during $4 \mathrm{yrs}$, has recently shown that cumulative exposure to $\mathrm{O}_{3}$ was associated to reduced growth in peak expiratory flow (PEF), as well as to FVC and FEV1 only among children spending more time outdoors [11]. Indoor sources of ozone are very rare and outdoor levels decreased rapidly in indoor air, indoor levels being very low. In the first South California study children playing three or more sports in communities with high ozone concentrations had a higher incidence of asthma than children performing less exercise, something which did not occur in low ozone communities [12]. Children performing strenuous exercise have a much higher exposure. Furthermore, a recent study in New England USA has shown that asthmatic children with maintenance medication are particularly vulnerable to low levels of ozone [13]. It could be then that a slowing of lung function growth due to ozone only occurs in some subgroups, those more exposed and those with asthma. In fact, chamber studies have demonstrated strong interindividual variation in pulmonary function responses to $\mathrm{O}_{3}$ [14]. Genes for quinone-metabolising enzymes may explain a different susceptibility in the pulmonary function response 
[15]. Identification of the more susceptible subgroups is a task that requires a large sample size, and probably collaborative studies.

In summary, IHORST et al. [10] have initiated epidemiological research into the persistent effects of ozone levels on lung-function growth, which is highly relevant from both public health and clinical perspectives. Further epidemiological studies need to follow this path, incorporating the new advances provided by investigations on exposure assessment and on susceptibility factors.

\section{References}

1. Wang X, Dockery D, Wypij D, et al. Pulmonary function growth velocity in children 6-18 years of age. Am Rev Respir Dis 1993; 148: 1502-1508.

2. Frischer T, Studnicka M, Gartner C, et al. Lung function growth and ambient ozone: A three-year population study in school children. Am J Respir Crit Care Med 1999; 160: 390-396.

3. Horak F Jr, Studnicka M, Gartner C, et al. Particulate matter and lung function growth in children: a 3-yr follow-up study in Austrian schoolchildren. Eur Respir J 2002; 19: 838-845.

4. Gauderman WJ, McConnell R, Gilliland F, et al. Association between air pollution and lung function growth in Southern California children. Am J Respir Crit Care Med 2000; 162: 1383-1390.

5. Peters JM, Avol E, Gauderman WJ, et al. A study of 12 Southern California communities with differing levels and types of air pollution. II Effects on pulmonary function. Am J Respir Crit Care Med 1999; 159: 768-775.

6. Liu L-JS, Delfino R, Koutrakis P. Ozone exposure assessment in a Southern California community. Environ Health Perspec 1997; 105: 58-65.

7. Geyh AS, Xue J, Ozkaynak H, Spengler JD. The Harvard Southern California chronic ozone exposure study: assessing ozone exposure of grade-school-age children in two Southern California communities. Environ Health Perspec 2000; 108: 265-270.

8. Delfino RJ, Coate BD, Zeiger RS, Seltzer JM, Street DH, Koutrakis P. Daily asthma severity in relation to personal ozone exposure and outdoor fungal spores. Am J Respir Crit Care Med 1996; 154: 633-641.

9. Navidi W, Lurmann F. Measurement error in air pollution exposure assessment. J Expo Anal Environ Epidemiol 1995; 5 : $111-124$.

10. Ihorst $\mathrm{G}$, Frischer $\mathrm{T}$, Horak $\mathrm{F}$, et al. Long- and mediumterm ozone effects on lung growth including a broad spectrum of exposure. Eur Respir J 2003; 22: 292-299.

11. Gauderman WJ, Gilliland GF, Vora H, et al. Association between air pollution and lung function growth in southern California children. Results from a second cohort. $\mathrm{Am}$ J Respir Crit Care Med 2002; 166: 76-84.

12. McConnell R, Berhane $\mathrm{K}$, Gilliland $\mathrm{F}$, et al. Asthma in exercising children exposed to ozone: a cohort study. Lancet 2002; 359: 386-391.

13. Gent JF, Triche EW, Holford TR, et al. Association of low-level ozone and fine particles with respiratory symptoms in children with asthma. JAMA 2003; 290: 1859-1867.

14. McDonnell WF. Intersubject variability in human acute ozone responsiveness. Pharmacogenetics 1991; 1: 110-113.

15. Bergamaschi E, De Palma G, Mozzoni P, et al. Polymorphism of quinine-metabolizing enzymes and susceptibility to ozone-induced acute effects. Am J Respir Crit Care Med 2001; 163: 1426-1431. 